\title{
Investigation of optimum conditions and costs estimation for degradation of phenol by solar photo-Fenton process
}

\author{
Mohamed Gar Alalm • Ahmed Tawfik • \\ Shinichi Ookawara
}

Received: 29 June 2014/ Accepted: 27 October 2014/Published online: 9 November 2014

(C) The Author(s) 2014. This article is published with open access at Springerlink.com

\begin{abstract}
In this study, solar photo-Fenton reaction using compound parabolic collectors reactor was assessed for removal of phenol from aqueous solution. The effect of irradiation time, initial concentration, initial $\mathrm{pH}$, and dosage of Fenton reagent were investigated. $\mathrm{H}_{2} \mathrm{O}_{2}$ and aromatic intermediates (catechol, benzoquinone, and hydroquinone) were quantified during the reaction to study the pathways of the oxidation process. Complete degradation of phenol was achieved after $45 \mathrm{~min}$ of irradiation when the initial concentration was $100 \mathrm{mg} / \mathrm{L}$. However, increasing the initial concentration up to $500 \mathrm{mg} / \mathrm{L}$ inhibited the degradation efficiency. The dosage of $\mathrm{H}_{2} \mathrm{O}_{2}$ and $\mathrm{Fe}^{+2}$ significantly affected the degradation efficiency of phenol. The observed optimum $\mathrm{pH}$ for the reaction was 3.1. Phenol degradation at different concentration was fitted to the pseudo-first order kinetic according to Langmuir-Hinshelwood model. Costs estimation for a large scale reactor based was performed. The total costs of the best economic condition with maximum degradation of phenol are $2.54 €$ / $\mathrm{m}^{3}$.
\end{abstract}

Keywords Compound parabolic collectors - Phenol · Photo-Fenton · Solar

M. Gar Alalm $(\bowtie) \cdot$ A. Tawfik

Department of Environmental Engineering, Egypt-Japan University of Science and Technology (E-Just), New Borg El Arab City, Alexandria 21934, Egypt

e-mail: mohamed.alkalla@ejust.edu.eg

\section{S. Ookawara}

Department of Chemical Engineering, Graduate School of Science and Engineering, Tokyo Institute of Technology, O-okayama, Meguro-ku, Tokyo 152-8552, Japan

\section{Introduction}

Phenol is one of the most prevalent pollutants in the wastewater of many industries such as resin industry, pharmaceuticals, polymerization inhibitors, petrochemical, paint, textile, oil refineries, antioxidants, and flavoring agents (Gernjak et al. 2003; Ayodele et al. 2012). Phenol is very toxic pollutant and considered as carcinogenic material that seriously endangers public health (Yang and Long 1999; Bekkouche et al. 2004). Because of its toxicity and low biodegradability, conventional biological treatment is not recommended as it needs long hydraulic retention time, nutrient addition and culture phenol degrading bacteria (Kusić et al. 2006).

It is reported that phenol and other bio-resistant organics can be removed by adsorption and membrane separation with high efficiency (Rana et al. 2013; Sunsandee et al. 2013). However, Adsorption in cases of high concentration and/or high industrial effluent discharge needs big amount of adsorbent and additional processes of adsorbent collection and regeneration are required (Dabrowski et al. 2005). Hollow fiber supported liquid membrane and bulk liquid membranes (BLK) proved high efficiency, lower energy consumption, and lower costs (Pancharoen et al. 2011; Wannachod et al. 2014). However, these technologies are still not spread in some of developed countries.

Advanced oxidation processes (AOPs) have been realized as particularly efficient technologies for degradation of phenolic compounds (Gernjak et al. 2003). In AOPs powerful reactive species like hydroxyl radicals $(\bullet \mathrm{OH})$ are generated by specific chemical reactions in aqueous solutions (Gar Alalm and Tawfik 2013). $(\bullet \mathrm{OH})$ is able to destroy even the most recalcitrant organic molecules and convert them into relatively benign and less persistent end products such as $\mathrm{CO}_{2}, \mathrm{H}_{2} \mathrm{O}$ and inorganic ions (Ballesteros 
Martín et al. 2009; Ahmed et al. 2011). Fenton reaction is an advanced oxidation technology that generates a highly reactive hydroxyl radical $(\bullet \mathrm{OH})$ by the combination of $\mathrm{Fe}^{2+}$ and $\mathrm{H}_{2} \mathrm{O}_{2}$ (Kavitha and Palanivelu 2004).

The photo-Fenton reaction can play an important role in oxidation process like the extraction and stripping reactions in membrane separation (Wongsawa et al. 2013; Suren et al. 2013). It typically enhances reaction rates and mineralization of recalcitrant organics than the dark reaction process and can take the advantage of UV irradiation from the solar light (Navarro et al. 2011; Vilar et al. 2012). In the reaction of the photo-Fenton process $\mathrm{Fe}^{2+}$ ions are oxidized by $\mathrm{H}_{2} \mathrm{O}_{2}$ to $\mathrm{Fe}^{3+}$ and one equivalent $\mathrm{HO} \bullet$ is produced (Lapertot et al. 2006; Elmolla and Chaudhuri 2010). In aqueous solutions the resulting $\mathrm{Fe}^{3+}$ act as the light absorbing species that produce another radical while the initial $\mathrm{Fe}^{2+}$ is reproduced as illustrated in Eqs. 1 and 2 (Feng and Le-cheng 2004). The resulted hydroxyl radicals have reduction potential $\mathrm{E}^{0}$ of $2.8 \mathrm{~V}$ (Moraes et al. 2004).

$\mathrm{Fe}^{+2}+\mathrm{H}_{2} \mathrm{O}_{2} \rightarrow \mathrm{Fe}^{+3}+\cdot \mathrm{OH}+\mathrm{OH}^{-}$

$\mathrm{Fe}^{+3}+\mathrm{H}_{2} \mathrm{O}+\mathrm{h} v \rightarrow \mathrm{Fe}^{+2}+\cdot \mathrm{OH}+\mathrm{H}^{+}$

According to the light sensitivity of the photo-Fenton reaction with respect to the solar spectrum, the utilization of a solar light source is considered to be very economic alternative as compared to UV lamps for treatment of wastewater at a full scale (Nogueira et al. 2012; Luna et al. 2013). Many researchers reported that compound parabolic collectors (CPC) technology is suitable for application of solar photo-Fenton process (Lafi and Al-Qodah 2006; Vilar et al. 2011; Souza et al. 2013) because UV light is reflected and intensified towards the solution moving in the reactor tubes (Gar Alalm et al. 2014).

The aim of this work was to evaluate photo-Fenton reaction for degradation of phenol. CPC reactor depending on the solar light was used. The effect of several parameters such as $\mathrm{pH}$, initial concentration, and Fenton reagent dosage was investigated. In addition, the pseudo-first order kinetic model was tested according to Langmuir-Hinshelwood model.

\section{Materials and methods}

\section{Chemicals}

Phenol and intermediate ring compounds such as catechol, hydroquinone, and p-benzoquinone were purchased from Merck (Germany) with purities $\geq 99 \%$. Ferrous sulphate hydrate $\left(\mathrm{FeSO}_{4} \cdot 7 \mathrm{H}_{2} \mathrm{O}\right)$, hydrogen peroxide $\left(\mathrm{H}_{2} \mathrm{O}_{2}\right)$, sulfuric acid, acetic acid glacial, and methanol was purchased from Sigma Aldrich company.
Experimental procedure

Photo-Fenton experiments were carried out using CPC reactor placed in Borg Alarab City, Egypt (latitude 30 $52^{\prime}$, longitude $29^{\circ} 35^{\prime}$ ) on the roof of environmental engineering department. The area of the photo-reactor module is $3,600 \mathrm{~cm}^{2}$ (Area of the outer tubes exhibited to solar light) and consists of six borosilicate tubes with diameter $2.5 \mathrm{~cm}$ and length $75 \mathrm{~cm}$ mounted on a curved polished aluminum reflector sheet with radius of curvature $9.2 \mathrm{~cm}$. The reactor is connected from both the inlet and outlet with a tank containing the phenol solution and provided with stirrer to ensure the homogeneity of feedstock. The solution was continuously pumped in a closed cycle by a flow of 1.5 $\mathrm{L} / \mathrm{min}$. A schematic diagram of the experimental set-up is shown in Fig. 1.

The reactor was fed with $4 \mathrm{~L}$ of the synthetic phenol solution with initial concentration of $100,200,500$, and $1,000 \mathrm{mg} / \mathrm{L}$. The $\mathrm{pH}$ was adjusted to by $\mathrm{H}_{2} \mathrm{SO}_{4}$, or $\mathrm{NaOH}$. Then $\mathrm{H}_{2} \mathrm{O}_{2}$, and $\mathrm{FeSO}_{4} \cdot 7 \mathrm{H}_{2} \mathrm{O}$ were added. A sample of $20 \mathrm{~mL}$ was taken every $10 \mathrm{~min}$ from the outlet of the reactor by the sampling port shown in Fig. 1. The solar irradiation was measured by Met one Portable Weather Station (Model Number 466A) installed in the same location. The normalized illumination time $\left(t_{30 \mathrm{w}}\right)$ was used to compare between photo-catalytic experiments instead of exposition time $(t)$. The normalized illumination time was calculated using the following equations (Malato et al. 2002; Lapertot et al. 2006).

$t_{30 \mathrm{w}, \mathrm{n}}=t_{30 \mathrm{w}, \mathrm{n}-1}+\Delta t_{\mathrm{n}}(\mathrm{UV} / 30)\left(V_{i} / V_{\mathrm{t}}\right)$

$\Delta t_{\mathrm{n}}=t_{\mathrm{n}}-t_{\mathrm{n}-1}$,

where $t_{\mathrm{n}}$ is the experimental time for each sample; UV is the average solar ultraviolet radiation $\left(\mathrm{W} / \mathrm{m}^{2}\right)$ measured during $\Delta t_{\mathrm{n}} ; t_{30 \mathrm{w}}$ is the normalized illumination time, which refers to a constant solar UV power of $30 \mathrm{~W} / \mathrm{m}^{2}$ (typical solar UV power on a perfectly sunny day around noon); $V_{\mathrm{t}}$ is the total reactor volume; and $V_{\mathrm{i}}$ the total irradiated volume.

Analytical methods

Phenol and oxidation intermediate ring compounds (catechol, hydroquinone and p-benzoquinone) were quantified by Shimadzu HPLC (Hayat et al. 2011) by C-18 phenomenex reverse-phase column, degasser (20A5), pump (LC-20AT), and prominences Diode Array Detector (SPDM20A). The samples were filtered by micro syringe filters $(0.2 \mu \mathrm{m})$. The mobile phase was a mixture of ultrapure water/methanol/acetic acid with volumetric percent ratio of 79.2:19.8:1.0. The flow rate of the mobile phase was $0.8 \mathrm{~mL} / \mathrm{min}$. The monitoring was at wave lengths of 270 , 
Fig. 1 Schematic diagram of the solar reactor

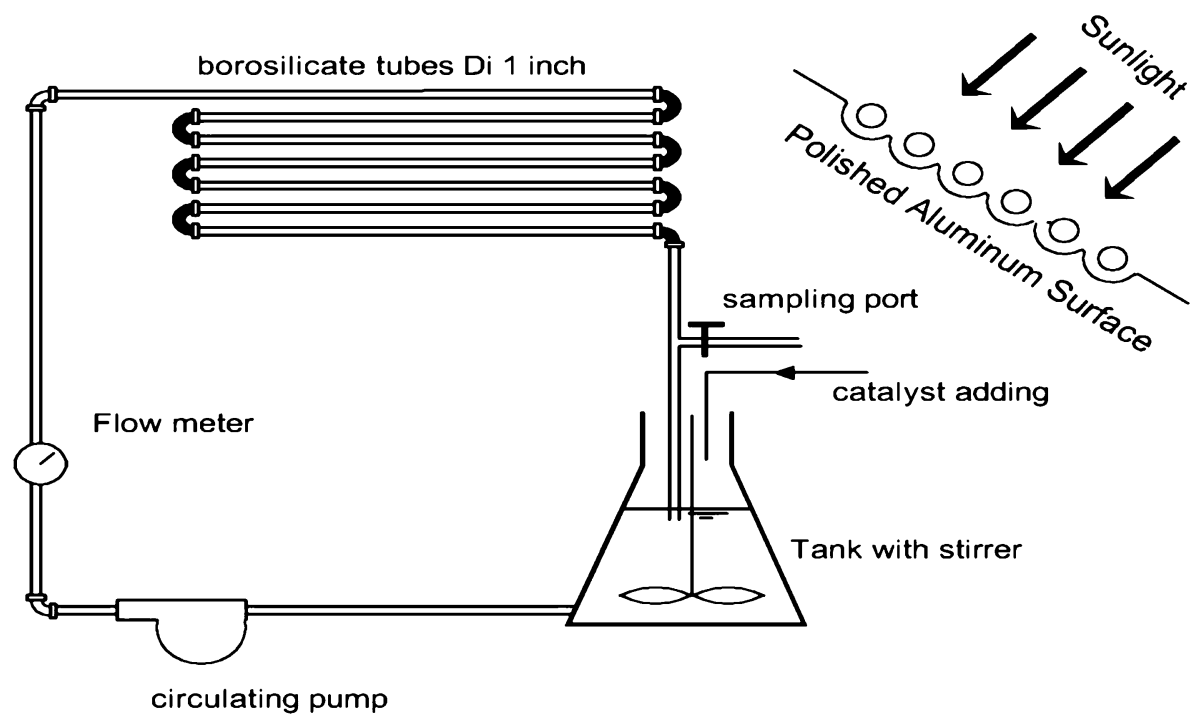

276, 290, and $245 \mathrm{~nm}$ for phenol, catechol, hydroquinone, and p-benzoquinone, respectively. Degradation efficiency of phenol was calculated as the percentage of removed amount to the initial concentration. $\mathrm{H}_{2} \mathrm{O}_{2}$ concentration was measured by $\mathrm{KMnO}_{4}$ titration method as explained by (Savarino and Thiemens 1999).

\section{Results and discussion}

Effect of irradiation time and initial concentration

Initial concentrations of phenol are essential to evaluate the extent of chemical degradation efficiency. Accordingly, the Effect of irradiation time at different initial concentration of phenol was observed and the results are shown in Fig. 2. The results obtained indicated that increasing the initial concentration of phenol detracted the degradation efficiency and prolonged irradiation time is needed for complete degradation. When the initial concentration of phenol was $100 \mathrm{mg} / \mathrm{L}$, complete degradation of phenol was achieved after $45 \mathrm{~min}$ of irradiation. Raising the initial concentration up to $200 \mathrm{mg} / \mathrm{L}$, complete degradation of phenol was also registered, but after $60 \mathrm{~min}$. However, further increase in the substrate concentration from 500 to $1,000 \mathrm{mg} / \mathrm{L}$ provided a degradation efficiency of 94 and $72 \%$, respectively, after $90 \mathrm{~min}$ of irradiation. These results correspond closely to other similar reported work (De et al. 2006). Decreasing of degradation efficiency at high concentration may be attributed to the consumption of Fenton reagent before oxidation process completed.

One of the major concerns of phenol degradation by AOPs is the nature and type of reaction end products and intermediates (Chiou and Juang 2007; Moreira et al. 2012). Moreover, to evaluate the oxidation process pathways and

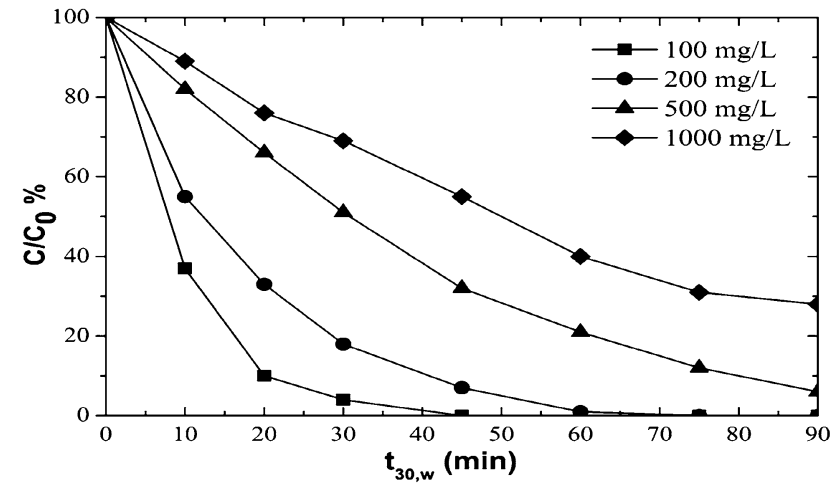

Fig. 2 Effect of irradiation time and initial concentration on degradation efficiency of phenol, $\mathrm{pH}=3.0, \mathrm{FeSO}_{4} \cdot 7 \mathrm{H}_{2} \mathrm{O}$ dose $=0.5 \mathrm{~g} / \mathrm{L}$, $\mathrm{H}_{2} \mathrm{O}_{2}$ dose $=44 \mathrm{mmol} / \mathrm{L}$

mechanism, it is important to identify oxidative products of the phenol during its photo-oxidation process. Various aromatic phenol intermediates including catechol, hydroquinone, and benzoquinone are the most reported to be appeared during phenol degradation (Bamuza-pemu and Chirwa 2013). Consequently, these compounds were also detected during photo-Fenton process and the results are illustrated in Fig. 3. The maximum concentrations of intermediates were detected and quantified at the first 20 min of irradiation. Concentrations of catechol, benzoquinone, and hydroquinone were 18,9 , and $4 \mathrm{mg} / \mathrm{L}$, respectively. After the first $20 \mathrm{~min}$, the concentrations of intermediates were significantly decreased as shown in Fig. 3. After $75 \mathrm{~min}$ the hydroquinone completely disappeared, while the remaining catechol and benzoquinone were only 4 and $2 \mathrm{mg} / \mathrm{L}$, respectively. Similar trends were observed in semi-continuous Fenton oxidation of phenol (Zazo et al. 2009). Decreasing of aromatic intermediates' concentrations is attributed to the further oxidation by 


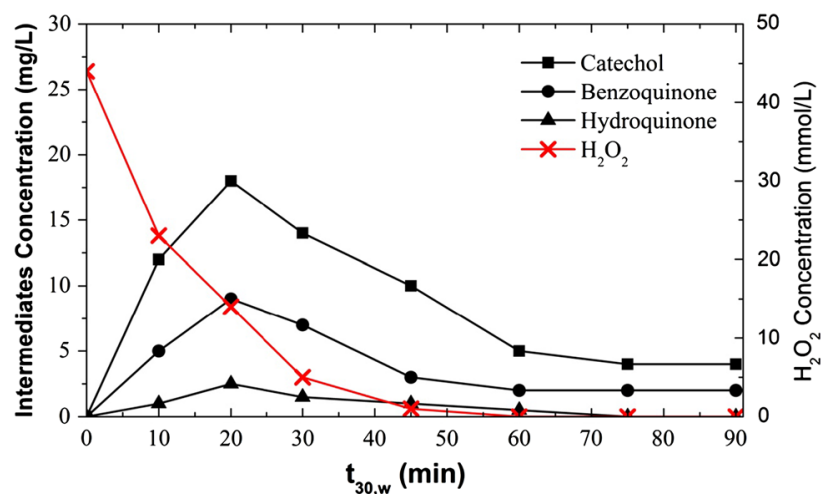

Fig. 3 Evolution of oxidation intermediates and $\mathrm{H}_{2} \mathrm{O}_{2}$ consumption, $\mathrm{pH}=3$, initial phenol concentration $=100 \mathrm{mg} / \mathrm{L}, \quad \mathrm{FeSO}_{4} \cdot 7 \mathrm{H}_{2} \mathrm{O}$ dose $=0.5 \mathrm{~g} / \mathrm{L}, \mathrm{H}_{2} \mathrm{O}_{2}$ dose $=44 \mathrm{mmol} / \mathrm{L}$

hydroxyl radicals to aliphatic acids and $\mathrm{CO}_{2}$ (Yavuz et al. 2007; Bach et al. 2010). The decomposition of $\mathrm{H}_{2} \mathrm{O}_{2}$ is also shown in Fig. 3. At the first $30 \mathrm{~min}$, the rate of $\mathrm{H}_{2} \mathrm{O}_{2}$ decomposition was higher due to the abundance of hydroxyl radicals. These results correspond to the phenol degradation profile at initial concentration of $100 \mathrm{mg} / \mathrm{L}$ shown in Fig. 2.

\section{Effect of initial $\mathrm{pH}$}

The oxidation potential of hydroxyl radicals is affected by the solution $\mathrm{pH}$. Accordingly, $\mathrm{pH}$ value has a considerable influence on Fenton reaction effectiveness (Badawy et al. 2006). Consequently the effect of initial $\mathrm{pH}$ on photoFenton degradation of phenol was extensively investigated by four different experiments with different initial $\mathrm{pH}$. The results are depicted in Fig. 4. The results revealed that the degradation efficiency of phenol was substantially improved under acidic conditions. The optimum initial $\mathrm{pH}$ was 3.1 in which complete degradation of phenol was achieved after 45 min of irradiation. However, at initial $\mathrm{pH}$ of 5.2 and 7.4 complete degradation of phenol occurred after 75 and 90 min, respectively. Executing the process at initial $\mathrm{pH}$ of 10.2 led to decrease the degradation efficiency to $80 \%$ after 90 min of light irradiation. This result could be due to low rate of decomposition of $\mathrm{H}_{2} \mathrm{O}_{2}$ at $\mathrm{pH}$ exceeding 4.0 which resulted in a drop of production of hydroxyl radicals ( $\mathrm{Li}$ et al. 2009).

\section{Effect of $\mathrm{H}_{2} \mathrm{O}_{2}$ and $\mathrm{FeSO}_{4} \cdot 7 \mathrm{H}_{2} \mathrm{O}$ dosage}

The extension of the Fenton reaction is mainly influenced by the $\mathrm{H}_{2} \mathrm{O}_{2}$ dosage, because it is the source of hydroxyl radicals during the light irradiation time (Zazo et al. 2009). The effect of variation of $\mathrm{H}_{2} \mathrm{O}_{2}$ dosage on degradation efficiency of phenol is shown in Fig. 5. The results revealed that increasing the dosage of $\mathrm{H}_{2} \mathrm{O}_{2}$ improved the

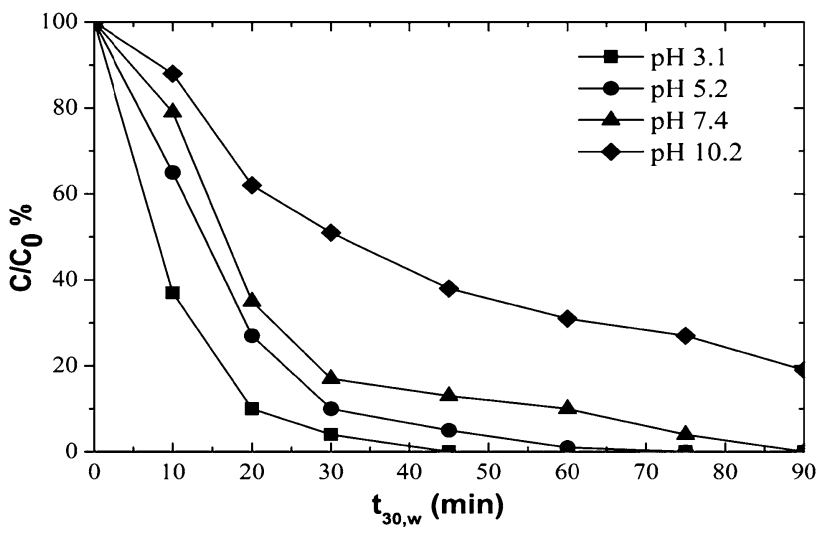

Fig. 4 Effect of $\mathrm{pH}$ on degradation efficiency of phenol, initial phenol concentration $=100 \mathrm{mg} / \mathrm{L}, \quad \mathrm{FeSO}_{4} \cdot 7 \mathrm{H}_{2} \mathrm{O}$ dose $=0.5 \mathrm{~g} / \mathrm{L}$, $\mathrm{H}_{2} \mathrm{O}_{2}$ dose $=44 \mathrm{mmol} / \mathrm{L}$

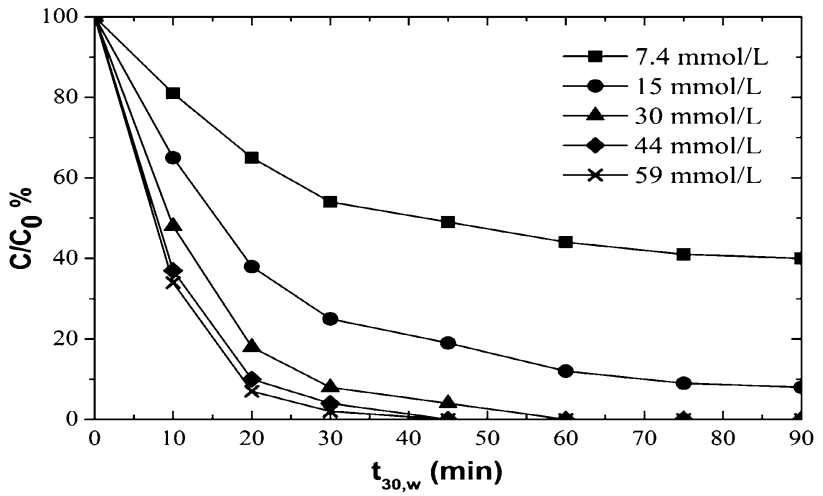

Fig. 5 Effect of $\mathrm{H}_{2} \mathrm{O}_{2}$ dose on degradation efficiency of phenol, $\mathrm{pH}=3.0$, initial phenol concentration $=100 \mathrm{mg} / \mathrm{L}, \mathrm{FeSO}_{4} \cdot 7 \mathrm{H}_{2} \mathrm{O}$ dose $=0.5 \mathrm{~g} / \mathrm{L}$

degradation efficiency of phenol. At $\mathrm{H}_{2} \mathrm{O}_{2}$ dosage of $7.4 \mathrm{mmol} / \mathrm{L}, 59 \%$ degradation of phenol was recorded, while complete degradation was registered at irradiation time of 60 and $45 \mathrm{~min}$ by raising the dosage to 30 and $44 \mathrm{mmol} / \mathrm{L}$, respectively. Raising the $\mathrm{H}_{2} \mathrm{O}_{2}$ dosage to $59 \mathrm{mmol} / \mathrm{L}$ provided no significant improvement of phenol degradation. Accordingly, the optimum $\mathrm{H}_{2} \mathrm{O}_{2}$ dosage is considered to be $44 \mathrm{mmol} / \mathrm{L}$.

It is clear from Eqs. 1 and 2 that the generation of hydroxyl radicals is also depending on the existence of $\mathrm{Fe}^{+2}$. In consequence of that, the influence of $\mathrm{FeSO}_{4} \cdot 7 \mathrm{H}_{2} \mathrm{O}$ was investigated and the results are shown in Fig. 6. The dosage of $0.1 \mathrm{~g} / \mathrm{L}$ revealed low reaction rate and achieved $77 \%$ degradation of phenol after 90 min of irradiation. Raising the dosage to $0.2 \mathrm{~g} / \mathrm{L}$ significantly improved the degradation efficiency to $92 \%$ in 90 min of irradiation. Complete degradation of phenol was recorded at a dosage of $0.5 \mathrm{~g} / \mathrm{L}$ in $45 \mathrm{~min}$ while at $\mathrm{Fe}^{+2}$ dosage of $0.8 \mathrm{~g} / \mathrm{L}$, a yellow color of the sample was detected which indicates excess of iron dosage. This behavior of $\mathrm{Fe}^{+2}$ and $\mathrm{H}_{2} \mathrm{O}_{2}$ 


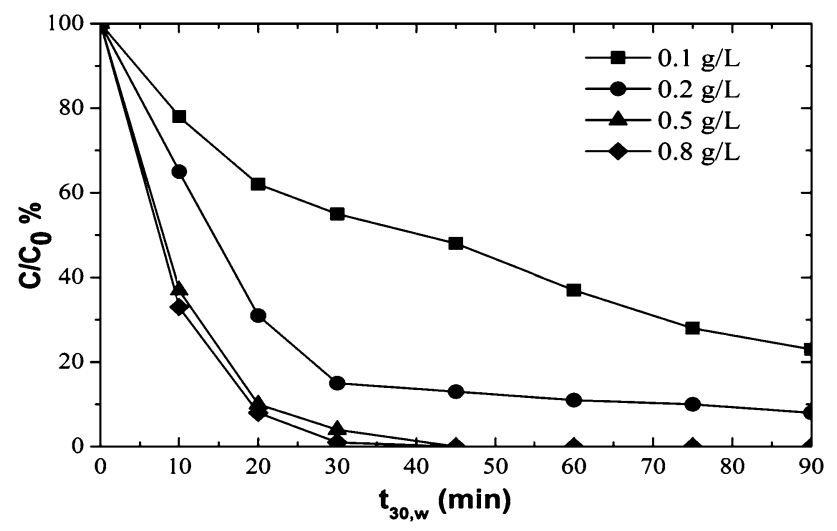

Fig. 6 Effect of $\mathrm{FeSO}_{4} \cdot 7 \mathrm{H}_{2} \mathrm{O}$ dose on degradation efficiency of phenol, $\mathrm{pH}=3.0$, initial phenol concentration $=100 \mathrm{mg} / \mathrm{L}, \mathrm{H}_{2} \mathrm{O}_{2}$ dose $=44 \mathrm{mmol} / \mathrm{L}$

dosage effect is close to the reported results in other works with some discrepancies in the dosage values according to the initial concentration of phenol and the reaction conditions (Yavuz et al. 2007; Zazo et al. 2009; Pontes et al. 2010; Nogueira et al. 2012).

\section{Degradation kinetics}

The Langmuir-Hinshelwood model is used to describe the kinetics of AOPs of organics in aqueous solutions (Shaban et al. 2013). It basically relates the degradation rate $(r)$ and reactant concentration $(C)$ in water at time $t$, which is expressed by the following equation (Kartal et al. 2001):

$r=-\frac{\mathrm{d} C}{\mathrm{~d} t}=\frac{K_{\mathrm{r}} K_{\mathrm{ad}} C}{1+K_{\mathrm{ad}} C}$,

where $k_{\mathrm{r}}$ is the rate constant and $K_{\text {ad }}$ is the adsorption equilibrium constant. The degradation curves of phenol by solar photo-Fenton reaction seem to be well fitted by mono-exponential relation, which can be appropriate to be described by pseudo-first order kinetic model. In addition, when the adsorption in the reaction is relatively weak and/ or the reactant concentration is low, Eq. 5 can be simplified to the pseudo-first order kinetics with an apparent firstorder rate constant $k_{\text {app }}$ :

$\ln \left(\frac{C_{0}}{C}\right)=K_{\mathrm{r}} K_{\text {ad }} t=K_{\text {app }} t$,

where $C_{0}$ is the initial concentration of phenol. Figure 7 shows the linear relation of $\ln \left(C_{0} / C\right)$ with irradiation time. $K_{\text {app }}$ and correlation coefficient $\left(R^{2}\right)$ were calculated for reaction at different initial concentrations of phenol and presented in Table 1 . The high $R^{2}$ values indicate suitability of applying Langmuir-Hinshelwood model on solar photo-Fenton reaction. The $K_{\text {app }}$ value was greater when the initial phenol concentration was higher, that

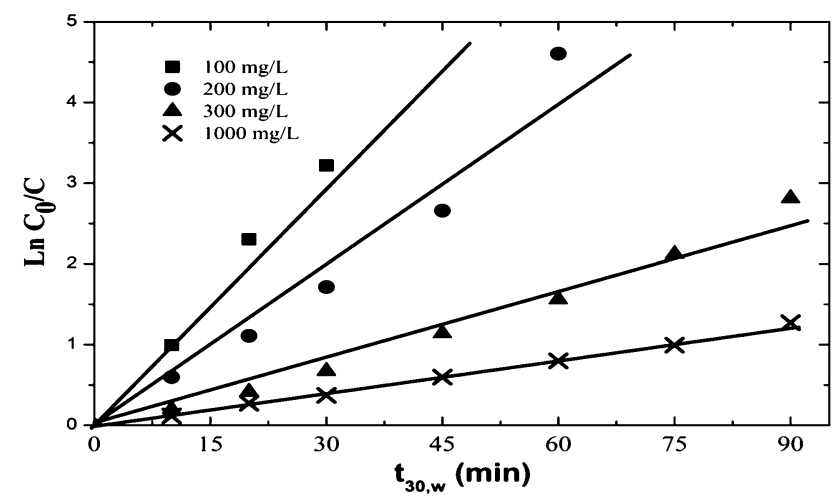

Fig. 7 Kinetics of solar photo-Fenton degradation of phenol, $\mathrm{pH}=3.0, \mathrm{FeSO}_{4} \cdot 7 \mathrm{H}_{2} \mathrm{O}$ dose $=0.5 \mathrm{~g} / \mathrm{L}, \mathrm{H}_{2} \mathrm{O}_{2}$ dose $=44 \mathrm{mmol} / \mathrm{L}$

Table 1 Reaction kinetics at different initial concentrations

\begin{tabular}{lll}
\hline Initial phenol concentration $(\mathrm{mg} / \mathrm{L})$ & $K_{\text {app }}$ & $R^{2}$ \\
\hline 100 & 0.109 & 0.995 \\
200 & 0.073 & 0.963 \\
500 & 0.03 & 0.985 \\
1,000 & 0.013 & 0.997 \\
\hline
\end{tabular}

corresponds to the results previously discussed in the effect of initial phenol concentration section.

\section{Economic and cost evaluation}

The decisions for industrial wastewater treatment plant are certainly influenced by the costs of treatment facilities (ElKamah et al. 2010). The optimization of operational conditions, i.e., irradiation time and dosage of reactants will not only affect the treatment process, but will also influence the implementation and running costs (El-Gohary et al. 2010).

In order to estimate the treatment cost, the experimental results obtained for were used to scale up a wastewater treatment plant for a case study of Mansoura Company of resins. The daily amount of wastewater is $30 \mathrm{~m}^{3} / \mathrm{d}$. Phenol concentration is $100 \pm 20 \mathrm{mg} / \mathrm{L}$. A solar photo-Fenton reactor is going to be studied. The capacity $(C)$ of the proposed reactor is estimated using Eq. 7 (Carra et al. 2013):

$C=V_{\mathrm{t}} \frac{t_{\mathrm{t}}}{t_{\mathrm{w}} D}$,

where $V_{\mathrm{t}}$ is the volumetric treated wastewater amount per year; $t_{\mathrm{t}}$ is the operation time for treatment reactor; $t_{\mathrm{w}}$ is the working time per day for the reactor; and Dis the number of working days per year. The treatment time is assumed to be $35 \%$ of working time. This assumption is based on the optimum irradiation time, and the average solar UV flux in the company site. The ratio of irradiated volume to the total 
Table 2 Cost estimation for removal of phenol at different conditions

\begin{tabular}{llllllll}
\hline $\begin{array}{l}\text { Phenol removal } \\
(R \%)\end{array}$ & $\begin{array}{l}\text { Irradiation time } \\
(\mathrm{min})\end{array}$ & $\begin{array}{l}\mathrm{H}_{2} \mathrm{O}_{2} \text { dose } \\
(\mathrm{mmol} / \mathrm{L})\end{array}$ & $\begin{array}{l}\mathrm{FeSO}_{4} \cdot 7 \mathrm{H}_{2} \mathrm{O} \\
\mathrm{dose}(\mathrm{g} / \mathrm{L})\end{array}$ & $\begin{array}{l}\text { Chemical costs } \\
\left(€ / \mathrm{m}^{3}\right)\end{array}$ & $\begin{array}{l}\text { Energy cost } \\
\left(€ / \mathrm{m}^{3}\right)\end{array}$ & $\begin{array}{l}\text { Operating costs }(\mathrm{OC}) \\
\left(€ / \mathrm{m}^{3}\right)\end{array}$ & $\begin{array}{l}\mathrm{Total} \text { costs } \\
\left(€ / \mathrm{m}^{3}\right)\end{array}$ \\
\hline 78 & 90 & 44 & 0.1 & 1.11 & 0.20 & 1.38 & 2.90 \\
92 & 90 & 44 & 0.2 & 1.13 & 0.20 & 1.40 & 2.92 \\
100 & 45 & 44 & 0.5 & 1.17 & 0.10 & 1.34 & 2.86 \\
60 & 90 & 7.4 & 0.5 & 0.30 & 0.20 & 0.57 & 2.09 \\
91 & 90 & 15 & 0.5 & 0.47 & 0.20 & 0.74 & 2.26 \\
100 & 60 & 30 & 0.5 & 0.82 & 0.13 & 1.02 & 2.54 \\
\hline
\end{tabular}

plant volume is assumed $75 \%$. The illumination area of the plant $\left(A_{\mathrm{p}}\right)$ is $2.1 \mathrm{~m}^{3}$.

Amortization costs of the investment (AC) and operating costs $(\mathrm{OC})$ per cubic meter of treated wastewater were considered. The amortization costs were calculated taking into account the basic constructing materials and the required equipments. The investment cost per year $(I)$ is calculated according to the illumination area of the treatment plant $\left(A_{\mathrm{p}}\right)$ and the wastewater treatment plant life cycle $(L)$ using Eq. 8 (Carra et al. 2013):

$I=\frac{A_{\mathrm{p}} C_{\mathrm{p}}}{L}$,

where $C_{\mathrm{p}}$ the cost per one $\mathrm{m}^{2}$ of the plant illuminated surface. A value of $800 € / \mathrm{m}^{2}$ is assumed for including the durable reflection surface, Pyrex tubes, construction of tanks, and other mechanical facilities (Carra et al. 2013). The amortization costs per $\mathrm{m}^{3}$ is calculated by Eq. 9 (Santos-Juanes Jordá et al. 2011):

$\mathrm{AC}=\frac{I}{V_{\mathrm{t}}}$

The operating costs include maintenance, the chemicals, and the energy consumed. However, the staff costs are not considered in this evaluation as the solar photo-oxidation treatment plant is independent on intensive manpower (Santos-Juanes Jordá et al. 2011) and also for the simplicity of the estimation. The maintenance costs are assumed to be $2 \%$ of the yearly investment according to previous studies (Muñoz et al. 2008; Molinos-Senante et al. 2010). The costs of chemicals including Fenton reagent and $\mathrm{pH}$ adjustment reagents are calculated as the concentration $\left(C_{i}\right)\left(\mathrm{kg} / \mathrm{m}^{3}\right)$ multiplied by the unit price $\left(P_{i}\right)(€ / \mathrm{kg})$. Prices of chemicals were taken as the average values according to local and international rates. The energy cost $(\mathrm{EC})\left(€ / \mathrm{m}^{3}\right)$ was calculated according to the power required for pumping wastewater in the treatment plant by Eq. 10:

$\mathrm{EC}=\frac{E P_{i} t_{\mathrm{w}} D}{V_{\mathrm{t}}}$,

where $E$ is the required power for circulating the effluent in the reactor and $P_{i}$ is the unit price of energy. It is assumed that the costs of energy is $0.12 € / \mathrm{kwh}$. The calculated costs of different operational conditions are illustrated in Table 2.

The amortization costs were $1.52 € / \mathrm{m}^{3}$ for all operational conditions according to the unified life cycle and daily amount of effluent. Table 2 shows that the operating costs were deeply influenced by dosage of chemicals and the needed irradiation time. Complete degradation of phenol was achieved in irradiation time of $45 \mathrm{~min}$ using $45 \mathrm{mmol} / \mathrm{L}$ of $\mathrm{H}_{2} \mathrm{O}_{2}$ and $0.5 \mathrm{~g} / \mathrm{L}$ of $\mathrm{FeSO}_{4} \cdot 7 \mathrm{H}_{2} \mathrm{O}$. The total costs of this condition were $2.86 € / \mathrm{m}^{3}$. However, reducing the dosage of $\mathrm{H}_{2} \mathrm{O}_{2}$ to $30 \mathrm{mmol} / \mathrm{L}$ with increasing the irradiation time to $60 \mathrm{~min}$ achieved the same degradation efficiency and the estimated costs were $2.54 € / \mathrm{m}^{3}$, so it is considered as the optimum condition.

\section{Conclusions}

The degradation of phenol from aqueous solutions by photo-Fenton process was investigated. The sunlight was utilized as a source of UV irradiation. At unified conditions the degradation efficiency of phenol was decreased with the increasing of initial concentration. However, complete degradation of phenol was achieved at initial concentrations of 100 and $200 \mathrm{mg} / \mathrm{L}$. Aromatic intermediates (catechol, benzoquinone, and hydroquinone) were grown up in the first 20 min of the reaction and then decreased due to oxidation by generated hydroxyl radicals. The degradation efficiency of phenol was improved under acidic conditions and the optimum $\mathrm{pH}$ was 3.1. Increasing the dosage of $\mathrm{H}_{2} \mathrm{O}_{2}$ and $\mathrm{FeSO}_{4} \cdot 7 \mathrm{H}_{2} \mathrm{O}$ considerably enhanced the degradation of phenol and the optimum dosages recorded were $44 \mathrm{mmol} / \mathrm{L}$ for $\mathrm{H}_{2} \mathrm{O}_{2}$ and $0.5 \mathrm{~g} / \mathrm{L}$ of $\mathrm{FeSO}_{4} \cdot 7 \mathrm{H}_{2} \mathrm{O}$. The obtained results at different initial concentrations of phenol fitted the pseudo-first order kinetic according to LangmuirHinshelwood model with high correlation. Using $30 \mathrm{mmol} /$ $\mathrm{L}$ of $\mathrm{H}_{2} \mathrm{O}_{2}$ and $0.5 \mathrm{~g} / \mathrm{L}$ of $\mathrm{FeSO}_{4} \cdot 7 \mathrm{H}_{2} \mathrm{O}$ for irradiation time of $60 \mathrm{~min}$ was the optimum economic condition. The total costs of this condition were $2.54 € / \mathrm{m}^{3}$. 
Acknowledgments The first author is grateful to the Egyptian ministry of higher education which provided him a full scholarship and to Japan International Cooperation Agency (JICA) for providing all the measurement facilities to participate in this work.

Open Access This article is distributed under the terms of the Creative Commons Attribution License which permits any use, distribution, and reproduction in any medium, provided the original author(s) and the source are credited.

\section{References}

Ahmed S, Rasul MG, Brown R, Hashib MA (2011) Influence of parameters on the heterogeneous photocatalytic degradation of pesticides and phenolic contaminants in wastewater: a short review. J Environ Manag 92:311-330. doi:10.1016/j.jenvman. 2010.08.028

Ayodele OB, Lim JK, Hameed BH (2012) Degradation of phenol in photo-Fenton process by phosphoric acid modified kaolin supported ferric-oxalate catalyst: Optimization and kinetic modeling. Chem Eng J 197:181-192. doi:10.1016/j.cej.2012. 04.053

Bach A, Shemer H, Semiat R (2010) Kinetics of phenol mineralization by Fenton-like oxidation. Desalination 264:188-192. doi:10. 1016/j.desal.2010.04.011

Badawy MI, Ghaly M, Gad-Allah T (2006) Advanced oxidation processes for the removal of organophosphorus pesticides from wastewater. Desalination 194:166-175. doi:10.1016/j.desal. 2005.09.027

Ballesteros Martín MM, Sánchez Pérez JA, Casas López JL et al (2009) Degradation of a four-pesticide mixture by combined photo-Fenton and biological oxidation. Water Res 43:653-660. doi:10.1016/j.watres.2008.11.020

Bamuza-pemu EE, Chirwa EMN (2013) Profile of aromatic intermediates of titanium dioxide mediated degradation of phenol. Chem Eng Trans 35:1333-1338. doi:10.3303/CET1335222

Bekkouche S, Bouhelassa M, Salah NH, Meghlaoui FZ (2004) Study of adsorption of phenol on titanium oxide (TiO2). Desalination 166:355-362. doi:10.1016/j.desal.2004.06.090

Carra I, Ortega-Gómez E, Santos-Juanes L et al (2013) Cost analysis of different hydrogen peroxide supply strategies in the solar photo-Fenton process. Chem Eng J 224:75-81. doi:10.1016/j.cej. 2012.09.067

Chiou C-H, Juang R-S (2007) Photocatalytic degradation of phenol in aqueous solutions by Pr-doped $\mathrm{TiO}_{2}$ nanoparticles. J Hazard Mater 149:1-7. doi:10.1016/j.jhazmat.2007.03.035

Dabrowski A, Podkościelny P, Hubicki Z, Barczak M (2005) Adsorption of phenolic compounds by activated carbon-a critical review. Chemosphere 58:1049-1070. doi:10.1016/j. chemosphere.2004.09.067

De AK, Dutta BK, Bhattacharjee S (2006) Reaction kinetics for the degradation of phenol and chlorinated phenols using Fenton's reagent. Environ Prog 25:64-71. doi:10.1002/ep.10104

El-Gohary F, Tawfik A, Mahmoud U (2010) Comparative study between chemical coagulation/precipitation $(\mathrm{C} / \mathrm{P})$ versus coagulation/dissolved air flotation $(\mathrm{C} / \mathrm{DAF})$ for pre-treatment of personal care products (PCPs) wastewater. Desalination 252:106-112. doi:10.1016/j.desal.2009.10.016

El-Kamah H, Tawfik A, Mahmoud M, Abdel-Halim H (2010) Treatment of high strength wastewater from fruit juice industry using integrated anaerobic/aerobic system. Desalination 253:158-163. doi:10.1016/j.desal.2009.11.013
Elmolla ES, Chaudhuri M (2010) Photocatalytic degradation of amoxicillin, ampicillin and cloxacillin antibiotics in aqueous solution using $\mathrm{UV} / \mathrm{TiO}_{2}$ and $\mathrm{UV} / \mathrm{H}_{2} \mathrm{O}_{2} / \mathrm{TiO}_{2}$ photocatalysis. Desalination 252:46-52. doi:10.1016/j.desal.2009.11.003

Feng HE, Le-cheng LEI (2004) Degradation kinetics and mechanisms of phenol in photo-Fenton process. J Zhejiang Univ Sci 5:198-205

Gar Alalm M, Tawfik A (2013) Fenton and solar photo-Fenton oxidation of industrial wastewater containing pesticides. 17th Int Water Technol Conf 2:5-7

Gar Alalm M, Tawfik A, Ookawara S (2014) Solar photocatalytic degradation of phenol by $\mathrm{TiO}$ 2/AC prepared by temperature impregnation method. Desalin Water Treat:1-10. doi:10.1080/ 19443994.2014.969319

Gernjak W, Krutzler T, Glaser A et al (2003) Photo-Fenton treatment of water containing natural phenolic pollutants. Chemosphere 50:71-78

Hayat K, Gondal MA, Khaled MM et al (2011) Nano ZnO synthesis by modified sol gel method and its application in heterogeneous photocatalytic removal of phenol from water. Appl Catal A Gen 393:122-129. doi:10.1016/j.apcata.2010.11.032

Kartal Ö, Erol M, Oğuz H (2001) Photocatalytic destruction of phenol by $\mathrm{TiO}_{2}$ powders. Chem Eng Technol 24:645-649

Kavitha V, Palanivelu K (2004) The role of ferrous ion in Fenton and photo-Fenton processes for the degradation of phenol. Chemosphere 55:1235-1243. doi:10.1016/j.chemosphere.2003.12.022

Kusić H, Koprivanac N, Bozić AL, Selanec I (2006) Photo-assisted Fenton type processes for the degradation of phenol: a kinetic study. J Hazard Mater 136:632-644. doi:10.1016/j.jhazmat.2005. 12.046

Lafi WK, Al-Qodah Z (2006) Combined advanced oxidation and biological treatment processes for the removal of pesticides from aqueous solutions. J Hazard Mater 137:489-497. doi:10.1016/j. jhazmat.2006.02.027

Lapertot M, Pulgarín C, Fernández-Ibáñez P et al (2006) Enhancing biodegradability of priority substances (pesticides) by solar photo-Fenton. Water Res 40:1086-1094. doi:10.1016/j.watres. 2006.01.002

Li R, Yang C, Chen H et al (2009) Removal of triazophos pesticide from wastewater with Fenton reagent. J Hazard Mater 167:1028-1032. doi:10.1016/j.jhazmat.2009.01.090

Luna AJ, Nascimento CAO, Foletto EL et al (2013) Photo-Fenton degradation of phenol, 2,4-dichlorophenoxyacetic acid and 2,4dichlorophenol mixture in saline solution using a falling-film solar reactor. Environ Technol 35:364-371. doi:10.1080/ 09593330.2013 .828762

Malato S, Blanco J, Cáceres J, Fernández-alba AR (2002) Photocatalytic treatment of water-soluble pesticides by photo-Fenton and $\mathrm{TiO}_{2}$ using solar energy. Catal Today 76:209-220

Molinos-Senante M, Hernández-Sancho F, Sala-Garrido R (2010) Economic feasibility study for wastewater treatment: a costbenefit analysis. Sci Total Environ 408:4396-4402. doi:10.1016/ j.scitotenv.2010.07.014

Moraes JEF, Quina FH, Nascimento CAO et al (2004) Treatment of saline wastewater contaminated with hydrocarbons by the photoFenton process. Environ Sci Technol 38:1183-1187. doi:10. 1021/es034217f

Moreira J, Serrano B, Ortiz A, de Lasa H (2012) A unified kinetic model for phenol photocatalytic degradation over $\mathrm{TiO}_{2}$ photocatalysts. Chem Eng Sci 78:186-203. doi:10.1016/j.ces.2012.04. 033

Muñoz I, Malato S, Rodríguez A, Domènech X (2008) Integration of environmental and economic performance of processes. Case study on advanced oxidation processes for wastewater treatment. J Adv Oxid Technol 11:270-275

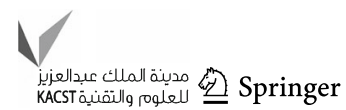


Navarro S, Fenoll J, Vela N et al (2011) Removal of ten pesticides from leaching water at pilot plant scale by photo-Fenton treatment. Chem Eng J 167:42-49. doi:10.1016/j.cej.2010.11. 105

Nogueira KRB, Nascimento CAO, Guardani R, Teixeira ACSC (2012) Feasibility study of a solar reactor for phenol treatment by the photo-Fenton process in aqueous solution. Chem Eng Technol 35:2125-2132. doi:10.1002/ceat.201200269

Pancharoen U, Leepipatpiboon N, Ramakul P (2011) Innovative approach to enhance uranium ion flux by consecutive extraction via hollow fiber supported liquid membrane. J Ind Eng Chem 17:647-650. doi:10.1016/j.jiec.2011.05.016

Pontes RFF, Moraes JEF, Machulek A, Pinto JM (2010) A mechanistic kinetic model for phenol degradation by the Fenton process. J Hazard Mater 176:402-413. doi:10.1016/j.jhazmat. 2009.11.044

Rana D, Matsuura T, Kassim MA, Ismail AF (2013) Radioactive decontamination of water by membrane processes - a review. Desalination 321:77-92. doi:10.1016/j.desal.2012.11.007

Santos-Juanes Jordá L, Ballesteros Martín MM, Ortega Gómez E et al (2011) Economic evaluation of the photo-Fenton process. Mineralization level and reaction time: the keys for increasing plant efficiency. J Hazard Mater 186:1924-1929. doi:10.1016/j. jhazmat.2010.12.100

Savarino J, Thiemens MH (1999) Analytical procedure to determine both $\delta 180$ and $\delta 170$ of $\mathrm{H}_{2} \mathrm{O}_{2}$ in natural water and first measurements. Atmos Environ 33:3683-3690

Shaban YA, El Sayed MA, El Maradny AA et al (2013) Photocatalytic degradation of phenol in natural seawater using visible light active carbon modified (CM)-n-TiO2 nanoparticles under UV light and natural sunlight illuminations. Chemosphere 91:307-313. doi:10.1016/j.chemosphere.2012.11.035

Souza BS, Moreira FC, Dezotti MWC et al (2013) Application of biological oxidation and solar driven advanced oxidation processes to remediation of winery wastewater. Catal Today 209:201-208. doi:10.1016/j.cattod.2012.08.037

Sunsandee N, Ramakul P, Pancharoen U, Leepipatpiboon N (2013) Enantioseparation of (S)-amlodipine from pharmaceutical industry wastewater by stripping phase recovery via HFSLM: Polarity of diluent and membrane stability investigation. Sep Purif Technol 116:405-414. doi:10.1016/j.seppur.2013.06.014

Suren S, Pancharoen U, Thamphiphit N, Leepipatpiboon N (2013) A generating function applied on a reaction model for the selective separation of $\mathrm{Pb}(\mathrm{II})$ and $\mathrm{Hg}(\mathrm{II})$ via HFSLM. J Membr Sci 448:23-33. doi:10.1016/j.memsci.2013.07.046

Vilar VJP, Pinho LX, Pintor AMA, Boaventura RAR (2011) Treatment of textile wastewaters by solar-driven advanced oxidation processes. Solar Energy 85:1927-1934. doi:10.1016/ j.solener.2011.04.033

Vilar VJP, Moreira FC, Ferreira ACC et al (2012) Biodegradability enhancement of a pesticide-containing bio-treated wastewater using a solar photo-Fenton treatment step followed by a biological oxidation process. Water Res 46:4599-4613. doi:10. 1016/j.watres.2012.06.038

Wannachod T, Leepipatpiboon N, Pancharoen U, Nootong K (2014) Separation and mass transport of $\mathrm{Nd}(\mathrm{III})$ from mixed rare earths via hollow fiber supported liquid membrane: Experiment and modeling. Chem Eng J 248:158-167. doi:10.1016/j.cej.2014.03. 024

Wongsawa T, Leepipatpiboon N, Thamphiphit N et al (2013) Fluidflow models operating on linear algebra for extraction and stripping of silver ions from pharmaceutical wastewater by HFSLM. Chem Eng J 222:361-373. doi:10.1016/j.cej.2013.02. 091

Yang GC, Long Y (1999) Removal and degradation of phenol in a saturated flow by in situ electrokinetic remediation and Fentonlike process. J Hazard Mater 69:259-271

Yavuz Y, Savas Koparal A, Bakir Ögütveren Ü (2007) Phenol removal through chemical oxidation using Fenton reagent. Chem Eng Technol 30:583-586. doi:10.1002/ceat.200600377

Zazo JA, Casas JA, Mohedano AF, Rodriguez JJ (2009) Semicontinuous Fenton oxidation of phenol in aqueous solution. A kinetic study. Water Res 43:4063-4069. doi:10.1016/j.watres. 2009.06.035 